Commentary on Combining Expressive Writing with an Affect-and Attachment-Focused Psychotherapeutic Approach in the Treatment of a Single-Incident Trauma Survivor: The Case of "Grace"

\title{
Assimilative Integration in the Treatment of Trauma
}

GEORGE STRICKER ${ }^{\mathrm{a}, \mathrm{b}}$

${ }^{\text {a }}$ Argosy University/DC

${ }^{\mathrm{b}}$ Correspondence concerning this article should be addressed to George Stricker, 1550 Wilson Boulevard, Ste. 600, Arlington, VA 22209.

Email: geostricker@gmail.com

\begin{abstract}
Erica Pass (2012) presents the case of Grace in which she assimilated Expressive Writing within an Accelerated Experiential Dynamic Psychotherapy approach to the treatment of a young woman reacting to a simple adult traumatic experience. Although the treatment might have been improved by more attention to the patient's angry feelings and cultural background, it was both creative and successful. The treatment provided a good example of the functioning of a Local Clinical Scientist.
\end{abstract}

Keywords: Assimilative integration; Accelerated Experiential Dynamic Psychotherapy; Expressive Writing; Local Clinical Scientist; case study; clinical case study

The psychotherapy offered by Erica Pass (2012) in the case of Grace consisted of a combination of Accelerated Experiential Dynamic Psychotherapy (AEDP; Fosha, 2002) and Expressive Writing (Pennebaker, 2004). AEDP is, itself, an example of psychotherapy integration in that it can be classified as theoretical integration because of the blending of psychodynamic psychotherapy and humanistic/experiential psychotherapy. In combination with Expressive Writing it becomes an example of assimilative integration, in that the central theoretical orientation, AEDP, assimilates the technique of Expressive Writing. That technique, relying on homework as it does, can be seen as having a home in cognitive-behavior therapy.

Pass began the course of psychotherapy using psychoeducation, explaining some of the interventions that would follow. This too is an assimilated technique, and is praiseworthy in that it is rare that a patient understands the mysteries of psychotherapy, and much time and resistance can be saved by simply being clear about what can be expected of the therapist, and what is expected of the patient. Pass also placed an emphasis on the positive, emphasizing the strengths of the patient where they existed. This is also an assimilated technique, this time from positive psychology (Seligman \& Csikszentmihalyi, 2000), as well as from newer developments in psychodynamic psychotherapy. Not only was Pass present as a support system for Grace, but she 
also encouraged the use of Grace's husband as a further support, thereby extending the treatment gains outside of the consulting room. This too is a praiseworthy effort.

I like to conceptualize psychotherapy from within the framework of enactments and corrective emotional experiences (Stricker \& Gold, 2005), and I believe that this course of treatment fits well into that scheme. First, regarding enactments, it can be expected that the patient will attempt to engage the therapist as an accomplice and, by doing so, create an enactment of previous familiar relationships. This is not done out of malice or resistance but simply because it is the accustomed manner of relating. One pattern for Grace was to repress emotional expression and then explode when she could no longer contain her feelings. Her parents may have taught this style to Grace, and they certainly colluded in it, because it was also their preferred way of handling difficulty. Grace also does not ask for help, attention, or care very easily, as much as it might be needed by her. Rather than allow this behavior and enter into an enactment, Pass encouraged Grace, partly by AEDP and partly through Expressive Writing, to put aside her successful but costly false self and find her true self. It is important that this was done in a supportive and understanding manner, so that it was not experienced as a threat or an assault. Pass also was very good at modeling a more engaged and effective manner of relating. She did this by her self-reflectivity, which encouraged Grace to be reflective as well. In addition, she removed the need for Grace to be a caretaker by acting as a caretaker herself, thereby freeing Grace to be more able to ask for and receive help and support.

Before moving on, it should be noted that the process was aided by Grace's position as the victim of a simple and relatively late in life trauma. As such, much adaptive functioning was already in place, and so it was easier to work with her than it might have been for a victim of an earlier or more complex trauma. Although some approaches to relating that were less successful, such as passivity, were in place, Grace appears to be a relatively healthy young woman with a superimposed trauma.

Let us now look at how a corrective emotional experience took place in the treatment. One task of the therapist is to avoid engaging in enactments, and by doing so, she can respond differently to the patient and, by doing this, provide a corrective emotional experience. Rather than allowing Grace to be alone with her demons, Pass was present as a secure attachment figure, and encouraged Grace to use her husband as such a figure as well. Fortunately, he was ready and able to do that, and his presence in Grace's life is testimony to the healthy substrate that she possessed. By not responding to Grace's repression with passivity and collusion, Pass was able to encourage Grace to become more emotionally expressive, and this was done within the context of a secure and supportive relationship. These corrective emotional experiences, extended outside the session, enhanced Grace's growth, and each positive experience laid the groundwork for further growth.

There are several other points that I would like to make about the course of treatment. I like the way Pass extended the session into the intersession period both by encouraging the relationship with her husband and by teaching Grace the value of self-soothing, a skill that will be of use in dealing with future stress. I also note how Pass did not set a specific script in the beginning, and then deviated from her initial general plan. For example, Pass postponed the onset of the writing component, delayed assignments that were directly about Grace's brother's 
suicide, shifted from a suicide assignment to free writing, and allowed Grace to determine the use of the first person in her writings. These are clear illustrations of how a manual cannot replace a skilled and empathic therapist.

At one point, Grace remarked that therapy was "my time to feel what I really feel, my own place to go." That is a very articulate way of phrasing therapy as providing a secure environment, and with the development of secure attachment, the possibility of exploration is developed and Grace was able to look for her true self and feel secure in developing it. Grace also noted that she and her husband were now a team again, and that her previous sense of being caught in a vicious cycle was now being replaced by what she referred to as a good cycle and what Wachtel (2011) has called a virtuous cycle. Just as dysfunctional behavior feeds upon itself and accelerates downward, interrupting that cycle can create a feedback loop that works in the other direction and allow for increasingly effective and satisfying behavior. Perhaps this enabling of a virtuous cycle and encouragement of skills such as reflectivity and self-soothing is why psychodynamic psychotherapy often shows increasing gains after treatment has terminated (Shedler, 2010).

I also noted, with approval, that Pass encouraged Grace, through Expressive Writing, to be the author of her own story. She also furthered this process by not providing Grace with answers to her questions, but instead encouraging her through judicious feedback to find her own voice, seek her own answers, and thereby, write her own story.

The matter of outcome measurement deserves some comment as well. Pass used the OQ45, which is well established in research (Lambert, 2007), and the Trauma Symptom Inventory (Briere, Elliott, Harris, \& Cotman, 1995), as pre-post measures to document the success of the treatment. Of course this was somewhat compromised by being a post and imagined pre measure, but there was little choice once the initial opportunity for measurement was missed. The success of the treatment was clear, but it would have been equally clear without the measurement. My preference is to use much shorter instruments, such as Duncan's Outcome Rating Scale and Session Rating Scale (Duncan, 2010), and to use them at each and every session. This allows me to track the trajectory of treatment and to be alert to either ruptures in the relationship or failures to make behavioral change. Therapists are not very good at being aware of this, and the knowledge of lack of progress or rupture allows for mid-course corrections and improved treatment.

Was there something that I might have approached differently? Yes, but without immediate knowledge of the patient, my surmise may be off base. Grace was told by a relative that her brother chose her room for the suicide because she was the person that he most hated. That hardly was a helpful or therapeutic intervention, and quite understandably upset Grace. However, it may not have been incorrect, and may resemble a poorly timed intervention, unsuccessful because of the faulty method of delivery rather than the incorrectness of the content. Suicide often is a hostile act, and the choice of place and time for the act is not random. I suspect that Grace's brother did harbor a good deal of animosity toward the sister who displaced him, and that Grace, in turn, also was angry at her brother for doing what he did, where he did it, and how he did it. It would have been a delicate matter to broach these feelings, but I suspect Grace's anger remains an important and untouched aspect of her functioning. 
I also regret that no mention was made of any cultural or religious aspect of Grace's world view. For many people, religion is a great source of comfort in times of stress. For many others, the stress raises questions of theodicy and threatens religious belief, compounding the loss that is experienced. It may be that Grace is not a religious person, but this would have been important to know. Similarly, cultures differ in how they handle loss, and without knowledge of Grace's background, we do not know if this was a source of strength or further pain for her. It is also interesting to note that the pseudonym given to this patient, whose religious beliefs are not mentioned, is Grace.

Finally, I have been asked to comment about how this case fits within my notion of a Local Clinical Scientist (LCS; Stricker \& Trierweiler, 1995). The LCS functions with the questioning attitude of the scientist, being a kind of Sherlock Holmes in the consulting room. The primary characteristics of the LCS are disciplined inquiry, critical thinking, imagination, rigor, skepticism, and openness to change in the face of evidence. They display a questioning attitude and search for confirmatory evidence; they apply research findings directly to clinical work; they undertake an evaluation of their individual practices; and they produce research, either collaboratively or more traditionally. Let us use this template to Pass's treatment of Grace. First, concerning displaying a questioning attitude and searching for confirmatory evidence, she seemed consistently to pose hypotheses, search for answers within Grace's responses, such as to the Expressive Writing tasks, and change course whenever it was called for. Second, concerning applying research findings directly to clinical work, Pass drew on the large body of attachment research (Shaver \& Mikulincer, 2008) and also on Pennebaker's basic research (Pennebaker, 1997) on the value of Expressive Writing. Third, undertaking an evaluation of her individual practice, Pass used two instruments to measure outcome. I already have noted my preferred approach to this task, but at least she made a serious effort to evaluate her work. Finally, as to producing research, the quality, systematic nature, and self-reflection present in Pass' case of Grace are all testament to her capacity to contribute to psychotherapy's case study knowledge base. My conclusion; Erica Pass qualifies as a Local Clinical Scientist, and as a damned good psychotherapist.

\section{REFERENCES}

Briere, J., Elliott, D. M., Harris, K., \& Cotman, A. (1995). Trauma symptom inventory: Psychometrics and association with childhood and adult trauma in clinical populations. Journal of Interpersonal Violence, 10, 387-401.

Duncan, B. L. (2010). On becoming a better therapist. Washington DC: American Psychological Association.

Fosha, D. (2002). The transforming power of affect: A model for accelerated change. New York: Basic Books.

Lambert, M. (2007). Presidential address: What we have learned from a decade of research aimed at improving psychotherapy outcome in routine care. Psychotherapy Research, 17, $1-14$. 
Pass, E. R. (2012). Combining expressive writing with an affect- and attachment-focused psychotherapeutic approach in the treatment of a single-incident trauma survivor: The case of “Grace.” Pragmatic Case Studies in Psychotherapy, 8(2), Article 1, 60-112. Available: http://hdl.rutgers.edu/1782.1/pcsp_journal

Pennebaker, J. W. (1997). Writing about emotional experiences as a therapeutic process. Psychological Science, 8, 162-166.

Pennebaker, J. W. (2004). Writing to heal: A guided journal for recovering from trauma and emotional upheaval. Oakland:CA: New Harbinger Press.

Seligman, M. E. P., \& Csikszentmihalyi, M. (2000). Positive psychology: An introduction. American Psychologist, 55, 5-14.

Shaver, P. R., \& Mikulincer, M. (2008). An overview of adult attachment theory. In J. H. Obegi \& E. Berant (Eds.), Attachment theory and research in clinical work with adults (pp. 1745). New York: Guilford Press.

Shedler, J. (2010). The efficacy of psychodynamic psychotherapy. American Psychologist, 65, 98-109.

Stricker, G., \& Gold, J. (2005). Assimilative psychodynamic psychotherapy. In J. C. Norcross, \& M. R. Goldfried (Eds.), Handbook of psychotherapy integration (2nd ed., pp. 221-240). New York: Oxford University Press.

Stricker, G., \& Trierweiler, S. J. (1995). The local clinical scientist: A bridge between science and practice. American Psychologist, 50, 995-1002.

Wachtel, P. L. (2011). Therapeutic communication: Knowing what to say when (2nd ed.). New York: Guilford. 